\title{
'Even though I Am Blind, I Am Still Human!': the Neglect of Adolescents with Disabilities' Human Rights in Conflict-Affected Contexts
}

\author{
Elizabeth Presler-Marshall $^{1} \cdot$ Nicola Jones $^{1}$ (D) Kifah Bani Odeh $^{1}$
}

Accepted: 8 November 2019/Published online: 28 November 2019

(C) The Author(s) 2019

\begin{abstract}
Drawing on qualitative research undertaken with adolescents with disabilities from refugee and host communities in Jordan and the State of Palestine, this article critically interrogates the framing of child neglect, which to date has situated the state as a protector rather than a perpetrator, the narrow understanding of adolescent needs and the responsibility of international actors for ensuring that the full range of human rights of adolescents with disabilities is supported. We frame our findings on adolescent neglect through a multidimensional capabilities lens and argue that although both adolescence as a distinct lifecycle stage and the rights of persons with disabilities have moved up the development agenda, adolescents with disabilities remain largely invisible, and especially so in conflict-affected contexts. Our findings highlight that adolescents with disabilities have limited access to schooling, skills building for economic empowerment and healthcare, due to accessibility challenges, cost and highly limited specialist provisioning. Moreover, adolescents with disabilities also have very little access to psychosocial support or opportunities to develop the independence which is a hallmark of adolescence and critical for successful transitions into early adulthood. Rather than working to meet those needs, the government and UN agencies tasked with provisioning in conflict-affected areas continue to miss opportunities to link young people with disabilities to existent services and tend to rely on NGOs to deliver smallscale, time-bound programming rather than assuming responsibility for appropriate programming at scale.
\end{abstract}

Keywords Adolescents $\cdot$ Disability $\cdot$ Neglect $\cdot$ State $\cdot$ Rights $\cdot$ Conflict

Nicola Jones

n.jones@odi.org.uk

1 GAGE, ODI, 203 Blackfriars Road, London SE1 8NJ, UK 


\section{Introduction}

Both disability and adolescence have moved up the development agenda in recent years, as it has become clearer that the former plays a key role in causing and perpetuating the cycle of poverty and exclusion (WHO and World Bank 2011; Aguilar 2017) and the latter has come to be seen as an 'age of opportunity' (UNFPA 2014) that offers scope to accelerate positive development trajectories into early adulthood. Despite this, however, adolescents with disabilities remain almost entirely invisible - with even the size and shape of the population not well understood. The neglect of this population highlights in turn the way in which the concept of neglect is too narrowly framed in international discourse. Specifically, international conventions focus on neglect as a form of maltreatment by parents which the state is under obligation to prevent - rather than acknowledging that the state itself has an obligation to provide supports and services and that failure to do so constitutes neglect in its own right.

To contribute to efforts to tackle these critical conceptual and evidence lacunae, this article draws on qualitative research undertaken with adolescents with disabilities from refugee and host communities in Jordan and the State of Palestine. Drawing on qualitative research undertaken with adolescents with disabilities from refugee and host communities, we critically interrogate the framing of child neglect, the narrow understanding of adolescent needs, and the responsibility of international actors to ensure that the full range of human rights of adolescents with disabilities is supported. The article begins by discussing three key elements that underpin the article's conceptual framing: disability as a development priority; adolescence as a window of opportunity to fast-track individual and collective development trajectories; and an understanding of neglect that goes beyond a narrow individual focus and draws attention to its structural dimensions. It then presents the research methodology and key findings from our primary research with adolescents with disabilities and their caregivers, before concluding and reflecting on policy and programming implications.

\section{Conceptual Framing}

\subsection{Disability as a Development Priority}

Disability is an evolving concept that includes long-term physical, mental, intellectual or sensory impairments acquired through injury, illness or congenital conditions (WHO and World Bank 2011). Impairments may have mild, moderate or severe impacts on daily functioning, depending not only on the nature of the disability but also on a wide range of personal (e.g. age, gender, socioeconomic status, ethnicity) and environmental (e.g. physical, social/cultural, political) characteristics. The international consensus is that disability should be understood as a phenomenon arising from the interaction between the individual with a health condition and the institutional, environmental and social factors that prevent them from enjoying their human rights and reaching their full potential (Rohwerder 2015).

Disability has moved up the development agenda in recent years, as it has become clear that it plays a key role in causing and perpetuating the cycle of poverty and 
exclusion (WHO and World Bank 2011; Aguilar 2017) and is associated with higher odds of a wide range of deprivation (e.g. education, healthcare, nutrition, water and sanitation, etc.) (Mitra et al. 2013). Research suggests that the relationship between poverty and disability appears particularly strong in cases where disability begins in childhood rather than developing in old age (Mitra et al. 2013, 2017), in part because childhood disability can lead to forgone wages for caregivers but primarily because children - and especially adolescents - with disabilities are likely to have limited access to the educational opportunities that would prepare them for gainful employment (UNESCO 2018).

Recognising the relationship between poverty and disability, governments and development agencies are increasingly promoting the inclusion of those with disabilities in social protection programming (Rohwerder 2015). Objectives, targeting and mechanisms vary from means-tested cash transfers that include but do not target those with disabilities to healthcare subsidies or educational stipends provided solely on the basis of disability. In the MENA region, programmes aimed categorically at those with disabilities are not uncommon, although they have been criticised for excluding the poorest and children (Abu Hamad et al. 2017; Devereux 2017; Jones et al. 2016). In particular, as van Diesen (2017) observes, the vulnerabilities of adolescents - who are going through a life-course stage involving tremendous change (GAGE Consortium 2017) - for 'transformative social protection' appear in many MENA countries to be underserved (p.25).

\subsection{Focusing on Adolescence}

Over the past decade, adolescence has become increasingly seen as an 'age of opportunity' (UNFPA 2014; Sheehan et al. 2017). A wide range of actors - from neuroscientists to development economists to UN agencies - have begun urging parents, schools, communities and national governments to look past the traditional 'deficit' model of adolescence and focus instead on how children's rapid maturation during the second decade of life can be leveraged to alter and accelerate positive development trajectories into early adulthood. A growing focus on adolescents' broader capabilities is core to much of this new work. Championed originally by Amartya Sen (1984), the capabilities approach has evolved as a broad normative framework exploring the kinds of assets (economic, human, political, emotional and social) that expand the capacity of individuals and collectives to achieve valued ways of 'doing and being'. By emphasising investment in the person as a whole, rather than focusing on a fixed bundle of external assets, the capabilities approach lends itself to an exploration of how to best invest in the most marginalised - such as adolescents with disabilities.

Although the evidence base is fledgling (Jones et al. 2018a; Groce and Kett 2014), adolescents with disabilities have been found to be disproportionately prone to challenges - in part because 'societal and cultural views of disability can take on additional meaning during the adolescent years', when young people become increasingly aware of individual differences and young people with disabilities are forced to more directly confront and balance their needs for autonomy and support (Maxey and Beckert (2017). However, even in the Global North there has been little attempt to methodically investigate the nexus of adolescence and disability - an oversight which has left many of the barriers to successful transitions to adulthood opaque and unaddressed (ibid.) and 
precluded agreement upon the indicators which are necessary for tracking progress over time. In the development literature, even as adolescence and disability have moved up the agenda individually, adolescents with disabilities have remained almost completely invisible (Jones et al. 2018a; Abu-Hamad et al. 2019).

Indeed, we lack even reliable estimates of children and adolescents with disabilities. WHO and the World Bank (2011) estimate that between 93 and 150 million young people under 18 years are living with a disability, with $5 \%$ of children under the age of 15 believed to be living with a moderate or severe disability on a global basis. ${ }^{1}$ Rates are slightly higher for adolescents, ${ }^{2}$ and are significantly higher in poorer countries, ${ }^{3}$ conflict-affected contexts, ${ }^{4}$ and countries where marriages between close relatives are common. In some countries in the MENA region, for example, up to $90 \%$ of some types of disability are caused by consanguinity (Bener and Mohammad 2017; Sirdah 2014).

\subsection{Conceptualising Neglect}

The global evidence base on 'neglect' is also very limited. Dubowitz (2014) notes that the 'neglect of neglect' is a longstanding cliché, with other forms of child maltreatment, especially physical and sexual abuse, taking centre stage in research agendas despite evidence that neglect is far more common. Research on neglect in the Global South is particularly rare, with Stalker and McArthur (2012) calling the evidence base in lowresource countries 'deplorable'. Much of the neglect of neglect is driven by the reality that neglect is a 'multifarious and socially constructed concept, and hard to measure' (Roche 2013: 113). Not only are other forms of child maltreatment intentional in contrast to neglect, which is fundamentally an act of omission, but neglect occurs on a continuum and can rarely be anchored to a specific event or moment in time (Coope and Theobald 2006; Tang 2008; Straus and Kantor 2005; Dubowitz et al. 2004; Dubowitz 2014). In addition, the concept of neglect is shaped by poverty and culture (Coope and Theobald 2006; Roche 2013; Tang 2008; Seth and Raman 2014). In subSaharan Africa, for example, families are not necessarily neglecting their children when they do not seek timely healthcare or provide adequate nutrition (Laird 2016a) or when they insist their children forgo schooling in favour of animal herding (Laird 2016b).

While incidence rates of neglect remain poorly explored in low- and middle-income countries, the concept of neglect has seen increasing attention in recent years as researchers have sought to move beyond the legal and medical understandings needed for referral and prosecution. The global community generally follows the lead of WHO (2006) - which considers neglect a form of child maltreatment because it results in 'actual or potential harm to the child's health, survival, development or dignity' (p. 9). Specifically, WHO (2006) defines neglect as: 'both isolated incidents, as well as a pattern of failure over time on the part of a parent or other family member to

\footnotetext{
${ }^{1}$ Of persons over the age of $15,19.4 \%$ are living with a moderate or severe disability (WHO and World Bank 2011).

${ }^{2}$ Because they have had more years to experience injury or illness that causes disability.

${ }^{3}$ WHO and World Bank (2011) estimate that rates of severe childhood disability are three times higher in lowand middle-income African countries than in high-income countries, for example (1.2\% versus $0.4 \%)$.

${ }^{4}$ In 2017 , the UN was able to verify that 360 children had been injured by conflict in Syria alone (UNICEF 2018).
} 
provide for the development and well-being of the child - where the parent is in a position to do so' (p. 10).

While there has been a longstanding debate on whether the concept of neglect should focus on parents' acts of omission or on the child's unmet needs (Dubowitz et al. 2004; Tang 2008; Seth and Raman 2014), and recent frameworks for understanding neglect have shifted to a more ecological approach that focuses on the interplay between individual, family, community and societal level factors (Landers 2013; Kalmakis and Chandler 2013), the onus of neglect has almost entirely remained on parents. Indeed, despite attention to the broader structural factors that shape parents' ability to care for their children, and efforts to avoid assigning blame where parents are overly constrained by forces beyond their control, only Coope and Theobald (2006) recognise 'governmental neglect', alongside physical, educational/ developmental and emotional neglect.

Government policy is central to conceptualising neglect, not only in humanitarian and development contexts, but also in the Global North given recent retrenchment of social programming. Parents cannot provide for the development and well-being of their children unless governments (and the international community) first create the systems and shape the infrastructure and spaces that allows them to do so. In the case of children and adolescents with disabilities, this includes not only legal protection from disability-related discrimination, but also strategic and adequately resourced services ensuring young people with disabilities 'have full enjoyment of all human rights and fundamental freedoms on an equal basis with other children'.

Framing neglect to include more structural dimensions requires shifts in the ways we interpret international conventions, which currently situate parents (or guardians) as perpetrators and the state as protector and take little to no account of the state's provision of services and programmes as it specifically relates to neglect. The UN Convention on the Rights of the Child ${ }^{5}$ (CRC), generally considered the backbone of international law regarding children and key to the UN Refugee Agency's (UNHCR) Executive Committee Conclusion on Children at Risk, ${ }^{6}$ is a case in point. While it specifies that children have a wide range of rights, including to protection, education and healthcare, and emphasises children's relationships with families and communities as core to their wellbeing, it discusses neglect only in terms of the state's duty to protect individual children from their parents' (or guardians') neglect (e.g. Article 19 and Section $g$ (vii) respectively). It does not address the state's obligation as duty bearer to create the enabling structures that prevent neglect on a wider basis. Similarly, although the UN Convection on the Rights of Persons with Disabilities ${ }^{7}$ calls on states 'to the maximum extent of their available resources' to 'provide early and comprehensive information, services and support to children with disabilities and their families' in order to prevent abuse and neglect - it again frames parents (or guardians) as neglectful and fails to frame state obligations in such a way that failure on behalf of the state to provide for young people with disabilities may constitute neglect in its own right.

\footnotetext{
${ }^{5}$ https://www.ohchr.org/en/professionalinterest/pages/crc.aspx.

${ }^{6} \mathrm{https} / / /$ www.unhcr.org/uk/protection/children/50f6d4746/unhcrs-executive-committee-conclusion-childrenrisk.html.

${ }^{7}$ https://www.ohchr.org/EN/HRBodies/CRPD/Pages/ConventionRightsPersonsWithDisabilities.aspx.
} 
In the case of children and adolescents in conflict-affected contexts, the challenge is greater still. The CRC calls for states to provide refugee children with 'appropriate protection and humanitarian assistance in the enjoyment of applicable rights', but the reality is not only that refugees are often not accorded the same rights as citizens in host countries, but that institutions engaged in child protection are chronically underresourced (Gerbaka and Almuneef 2014). This leaves UN agencies and other humanitarian organisations to assume the mantle of rights' protectors - under conditions that are increasingly resource-constrained due to the protected nature of recent conflict (World Bank 2017). While these humanitarian actors recognise that children and adolescents 'are more likely to be sidelined in every aspect of humanitarian assistance' (UNDESA n.d.), as of yet the unique needs of children and adolescents with disabilities in conflict-affected contexts have scarcely been recognised (Jones et al. 2016). Indeed, even UNICEF's Core Commitments for Children in Humanitarian Action ${ }^{8}$ mention children with disabilities just once, only noting that they have special needs that require targeted interventions.

\section{Methodology}

To contribute to global efforts to strengthen understanding of the challenges that young people with disabilities face, and to identify opportunities and priorities for action, this article draws on research undertaken as part of the Gender and Adolescence: Global Evidence (GAGE) research programme in Jordan and Palestine. GAGE is a multicountry, mixed-methods longitudinal study focused on adolescent transitions and the ways in which they shape young people's broader capabilities (GAGE Consortium 2017). The overarching GAGE sample, which encompasses 18,000 adolescents and 17,000 caregivers, living in 6 countries in the Global South. It was designed to allow for in-depth exploration of disability and the impacts of varying types of impairments on adolescent lives through the inclusion of a nested sample of 1000 adolescents with disabilities (Jones et al. 2018c; Abu-Hamad et al. 2019).

The current paper draws on GAGE research conducted in Jordan and Palestine, where our qualitative sample of approximately 450 adolescents (aged 10-19) includes 132 with disabilities and their female caregivers. Those adolescents, who have a range of hearing, vision, physical, and intellectual impairments, are equally divided between girls and boys and span the second decade of life in terms of age. Data was collected using a variety of interactive and participatory tools - including a 'favourite things' exercise and a social support exercise with individual adolescents, and, with groups, body mapping, community mapping and vignettes exercises to explore more culturally sensitive issues, including stigma against people with disabilities (see Jones et al. 2018b). Data were collected across a variety of contexts, including refugee camps, informal tented settlements and host communities, and tools were adapted depending on the type of impairment adolescent respondents had. Research ethics approval was secured from the Overseas Development Institute's Research Ethics Committee and from the United Nations High Commissioner for Refugees in Jordan (UNHCR).

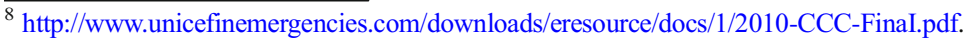


Transcripts were translated into English and then read and coded using qualitative analysis software MaxQDA by a small team, following a codebook shaped around the GAGE conceptual framework and the research tools. Analysis was undertaken by researchers familiar with gender and adolescence, disability, and the MENA region, following the GAGE conceptual framework. Care was taken during analysis to identify cross-cutting themes - whilst also allowing space for dissenting voices more specific to individual experiences.

\section{Our Findings}

Overall our research findings highlight how neglected the broader capabilities of adolescents with disabilities living in Jordan and Palestine are. Although a minority have access to quality education and healthcare, and enjoy opportunities to socialise with their peers and learn skills that will serve them in the future, the majority appear to have little access to the rights envisioned by the CRC. Indeed, many have never had the opportunity to attend school and especially adolescent girls - who face intersecting disadvantages due to discriminatory gender and social norms - spend the bulk of their time isolated at home with little but television to distract them. Largely invisible even to the social protection programmes meant to serve as a safety net to the most vulnerable, 'they only have God' (mother of a 14-year-old Syrian girl with a vision impairment).

\subsection{Education and Learning}

Our findings indicate that a minority of adolescents with disabilities appear to have access to quality education. Some attend schools for the blind that are 'incredible' (mother of an 8th grade Jordanian girl who is blind) or have found principals who are 'kind and gentle' and willing to move classes 'from the upstairs to the ground floor' (mother of a 15-year-old Syrian boy who has a mobility impairment). A few attend schools, like an UNRWA secondary school in Jordan, that give 'a lot of attention to people with disabilities', including even 'hearing devices to assist the student with hearing disabilities' (Palestinian refugee girl with a physical impairment living in Jordan). Indeed, in Palestine, a 16-year-old boy who is blind noted that the Palestinian Ministry of Education had made sure that his school would work to meet his needs, by training the teachers at his government school to help them 'understand how to help someone who has a visual disability'.

Critically, in terms of focusing on the more structural aspects of neglect, most adolescents with disabilities who are receiving quality education have highly committed parents with some resources who have fought to ensure their children have access to appropriate services. For example, a Palestinian refugee woman, whose daughter has vision and hearing impairments, explained that when the school refused to register her child, she went to the Jordanian Ministry of Education and 'sat on the floor... and told them I was not leaving'. A father in the West Bank related a similar story. When he went to the Ministry of Education, to find out what schools were available for his eighth-grade daughter with a hearing impairment, he was told that it would be necessary to wait 'for a donor to handle this'. He 'tore up the papers' and took matters into his own hands, moving closer to town and hiring a private driver to get his 
daughter to school in Ramallah. In short, state provisioning of appropriate services is not a right that is widely realised - but rather one that can be obtained through exceptional effort.

For many other adolescents with disabilities who are attending (or have attended) school, quality concerns were a common response. In Palestine, those concerns largely revolved around poor-quality teaching and the limited efforts made to accommodate the learning needs of adolescents with disabilities - especially at government schools, where overcrowding is amplified by the disability-related stigma of staff and students. Students spoke of teachers who do not allow them to participate in science labs because they have 'low expectations for me' (16-year-old Palestinian boy who is blind), 'do not really put much effort in helping us' (19-year-old adolescent girl with a vision impairment), or that 'only care about the one who got the highest marks' (18-yearold adolescent girl with a mobility impairment). An 18-year-boy with a mobility impairment, when asked why he left school after sixth grade, explained that they 'did not learn much', while a 16-year-old boy who is blind explained that while he has a Braille typewriter, he is not allowed to use it at school because it is 'loud and annoys other students'. Palestinian adolescents also spoke of a lack of affordable and accessible transportation and rampant 'verbal abuse towards people with disabilities' (16-year-old boy who is blind) at school. Indeed, the mother of a 17-year-old intellectually impaired girl reported that 'even the teacher and janitor bullied my daughter'.

In Jordan, where many adolescents told us that teachers and principals do not tolerate bullying at school and 'punish all the bullies' (Palestinian refugee girl with a mobility impairment), quality concerns were more muted among respondents. Because it took several years for educational opportunities to scale up to accommodate need, Syrian adolescents with disabilities who are enrolled in school are largely grateful for the opportunity to attend school at all. Many of the Jordanian students included in our sample attend special needs schools in the capital or larger cities or private schools both of which require greater parental resources in terms of transport and fees. For those in mainstream schools, several adolescents with disabilities who are living in Jordan mentioned that they had access to only a single room at school, meaning that they could not attend science lab, sports class, or eat in the cafeteria. Others reported that those with severe vision impairments have limited opportunities to choose what to study in secondary school. As maths and science are not taught in Braille, they 'can only study the art stream subjects' (18-year-old Syrian girl who is blind).

More concerning is the fact that Syrian adolescents with disabilities living in Jordan are very often still out of school, even though the Government of Jordan and the international community have moved mountains to scale up educational opportunities. Our research found that in part this is because government policy stipulates that those who have been out of school for more than three years may not access formal education without first taking 'catch up' classes - and these classes are rarely available to adolescents with disabilities. Parents reported that when they first arrived in Jordan with their children, on average five years ago, there was 'no Braille here' (Syrian mother of two adolescents with vision impairments) or 'there are no centres for deaf people' (Syrian mother of three adolescents who are deaf). The mother of an 18-yearold boy who requires a wheelchair was told by the local school that that they could not accommodate her son's needs, a gap which she felt was partly informed by discrimination against the refugee community: 'They would put in so much more effort to make 
a section for him and teach him if he were a citizen instead of a refugee.' Where parents were able to locate schools that could accommodate their children's learning needs, costs were often prohibitive. Fees were '80 to 90 dinars! ... [F] amilies can't afford this!" exclaimed the mother of a 14-year-old Syrian girl who is deaf. Other Syrian adolescents with disabilities are excluded from education because of mobility constraintsconstraints that could be relieved if social protection programming was better targeted and indexed to account for the different and often higher needs of those with disabilities. For example, those who live on the second or third floor, where rents are lower, are often too heavy for parents to carry up and down to the bus, meaning that a cash transfer to compensate for rent differentials could help improve children's access to school. The mother of a 12-year-old with a mobility impairment explained, 'We can put her in a bus to take her, it's putting her in that's an issue. Our house has a staircase. Carrying her is hard. And if it's on the ground floor, its expensive.'

Parents and adolescents recognised that adolescents with disabilities, especially those who have been shut out of formal education, need access to other forms of learning, such as vocational training programmes, if they are to have independent futures. Indeed, the mother of two Syrian adolescents who are deaf explained that one of the things that she loves most about her son's school is that 'they send the children to learn craftsmanship' in addition to academic classes. However, although a few young people had participated in programmes that taught skills such as hair styling, ceramics and mobile repair, and one even had a driver that "coordinated with him to come each Sunday so he would pick up the wheel chair' (18-year-old Syrian boy with a mobility impairment), most had no access to any sort of training programme. Research participants reported 'they [charities] fund microfinance projects but not for people with disabilities' (18-year-old Syrian girl who is blind) and that even when young people with disabilities sign up for training, they 'will not be picked [because trainers] will choose a person who can speak' (Syrian mother of several adolescent daughters who are deaf). Girls with disabilities reported that they had particularly limited access to programming, given that gender norms common across the region tend to see very few types of jobs as acceptable for females. For example, a 19-year-old Palestinian girl with a vision impairment explained that 'Although I considered doing embroidery and sewing, I was told that I cannot work on a machine because I might hurt myself.'

An additional layer of neglect that adolescents with disabilities face in realising their right to an education and learning in conflict-affected Jordan and Palestine is the limited efforts expended by humanitarian actors and the international community to mitigate the exclusion of these young people. In Palestine, Israeli occupation limits access to education and training for many adolescents with disabilities. A 15-year-old adolescent girl with a hearing impairment from the West Bank highlighted the challenges of the Israeli military checkpoints which she has to pass daily en route to school: 'There are checkpoints... There are Israeli soldiers on the way and it is dangerous. I feel scared of the soldiers, but that does not prevent me from going to school.' Indeed, an 18-year-old adolescent girl explained that despite her family's efforts she eventually dropped out of secondary school as there was no reliable public transport in Area $\mathrm{C}^{9}$ of the West Bank

\footnotetext{
${ }^{9}$ Area $\mathrm{C}$ is an administrative division of the West Bank, set out in the Oslo II Accord. Over $60 \%$ of the West Bank is considered Area C, where Israel retains near exclusive control, including over law enforcement, planning and construction.
} 
and private taxi drivers routinely discriminated against her on account of her disability. She reported: 'The worst year was the eleventh....The transportation got harder. Sometimes I wet myself on my way home. The school was very far, and it was hot.... I would leave school at 1:30 and reach home at $3 \mathrm{pm} . .$. . My parents used to give me more money for a taxi, but the cars didn't stop for me.'

In Jordan, UN agencies regularly visit refugee households to assess vulnerability and inform social protection programme targeting. However, the majority of caregivers included in our research reported that although UNHCR or UNICEF had 'called us many times to take data... they don't come back with services' (Syrian mother of three adolescents who are deaf). Indeed, even when parents tell enumerators that their children are out of school because they cannot find a school that can accommodate their children's needs, enumerators fail to inform them what options exist near their homes. 'We said there is no place for him. But they didn't provide any support or information,' reported the mother of an 18-year-old Syrian boy who has a mobility impairment. Many Syrian adolescents with disabilities have been out of school since they arrived in Jordan - and their parents see no way for them to return and have neither the knowledge nor confidence to press for improved services.

\subsection{Healthcare and Nutrition}

Echoing our findings regarding education and learning, the majority of adolescents with disabilities included in our research reported that their access to general as well as specialised healthcare - and sometimes nutrition - was significantly compromised. Barriers included cost, poor quality, and unsustainability and were almost without exception higher for young people with than without disabilities due to the greater needs, deeper poverty, and more limited accessibility of the former.

Most caregivers of adolescents with disabilities highlighted costs - of care, medication, disposables, and transportation - as the main barrier to health care. With free and subsidised care (or insurance) not uniformly available to either those with disabilities or those who are poor, and health care costs for those with disabilities generally higher than those without disabilities, some families were forced to forgo care for their children and others were pushed into debt to afford it. This was particularly the case with refugee families, who are often caught in 'no-man's' land in terms of rights. The mother of an 11-year-old boy with a mobility impairment, for example, who has no access to the Jordanian public health system because as refugees from Gaza they are denied citizenship rights explained, 'I cannot send him to physiotherapy; it is so costly because we have no health insurance and I am a widow.' While even routine care, such as for a thyroid disorder, can be out of reach for the poorest families, especially when the cost of private transportation is factored in, complex medical treatment is especially hard to access. The mother of a 12-year-old Syrian girl with a mobility impairment reported that her daughter had not received the calcium injections that she needs to treat her osteoporosis for a year and half, because as the UNHCR has been forced to cut back on services, due to budget shortfalls, she has been left with co-pay that far exceeds her monthly income: 'each dose costs 800 JD [\$1,128 USD]'. A 14-year-old Syrian girl who is blind reported that while she had been told that her vision was correctable, her father could not afford 'cornea implant surgery' which is only available in private 
hospitals. The Syrian mother of two children who are profoundly deaf explained that her family is still in debt after paying for them to receive cochlear implants, which each cost ' 16 thousand [dinars] after the discount'.

Costs are also a barrier to adequate nutrition for adolescents with disabilities in Palestine and Jordan. Many families reported that they were only sometimes able to afford meat, vegetables or fruit, leaving their children at risk of micro-nutrient deficiency even as cash transfer programmes meant to stave off food insecurity denied them benefits because they were inadequately targeted to include those with disabilities. The mother of several visually impaired adolescent daughters explained, 'We applied in every way we can and no one helped us.' Several caregivers of adolescents with disabilities with particularly complex feeding needs highlighted that their children are at risk of not only malnutrition, but hunger, because they cannot afford to purchase they types of food that their children can eat. In Jordan, for example, the Syrian mother of two adolescents with multiple and severe disabilities reported that her children, who have difficulty swallowing and require soft foods and bottles, are not getting the yogurt and milk that they need. She added that she has invested significant effort in trying to demonstrate need in order to get UNHCR to provide her with a cash transfer to help her afford to feed her children. 'He [a cash transfer programme implementer] gave me about 7-8 numbers. I called them all, but they were closed.'

Alongside concerns about costs, our research found that in both countries public health care systems and NGO run clinics are overwhelmed and often unable to consistently deliver quality services, which impacts adolescents with disabilities more than those without because the former are more likely to need services. In Jordan, the mother of a 15-year-old Syrian boy with paraplegia explained that 'physiotherapy centres in the public sector [had been] unsuccessful' and that they had chosen to do therapy at home instead. The Syrian mother of three adolescents who are deaf added that while her children 'receive their treatment in the International Health Commission... they didn't give us the medications for eight months'. In Palestine, concerns about the quality of care also included providers who were unkind or disrespectful because of disability-related stigma. An 18-year-old Palestinian girl with a mobility impairment reported that she was treated less gently than her abled-bodied peers: 'They don't give me the injections properly. They used to hurt me,' she said.

Another common challenge identified by families involved in our research is that the best disability-specific medical care is rarely available over the longer term because it is often provided by NGOs that have small budgets and short funding cycles. In Jordan, 'This is the problem we suffer from. No continuity,' explained the mother of a 15-yearold Syrian boy with a mobility impairment. Similarly, the caregiver of an 18-year-old Syrian boy with a mobility impairment reported that for two years he had received 'excellent' therapy at a centre that focused on those injured in the war, but this abruptly ended when funding ran out. While international disability-focused NGOs such as Handicap International have provided a variety of ad-hoc support to Syrian refugees with disabilities, such as electric wheelchairs and short courses aimed at caring for those with disabilities, most of this support was years in the past, 'at the beginning upon our arrival to Jordan' (mother of a 15-year-old Syrian boy with a mobility impairment). The disability sector in Palestine is more developed. However, it too suffers from systemic neglect. This research, as well as previous research undertaken by the authors (Jones et al. 2016; Abu-Hamad et al. 2019), found that nearly all services are provided 
by community-based organisations, with the government's role largely limited to reimbursement.

\subsection{Psychosocial Well-Being}

The most neglected capability domain among adolescents with disabilities in Jordan and Palestine is psychosocial well-being. Research participants highlighted that many young people, particularly girls, have exceptionally limited opportunities to engage with peers, either informally in the community or through structured adolescentfocused programming. Young people's social isolation is compounded by the fact that when they do leave home, many are verbally abused due to high levels of disabilityrelated stigma. Even though adolescents have been exposed to high levels of stress, trauma, and violence as a result of the refugee crisis in Jordan and the protracted humanitarian crisis in Palestine, access to formal psychosocial support for adolescents with disabilities is effectively non-existent. While we found that most adolescents feel supported by their parents and siblings, we also discovered that many mothers, especially those with more than one child with disabilities and those who are under the greatest levels of financial stress, are exhausted and sometimes not able to focus on the needs of their adolescents.

\subsubsection{Adolescent Psychosocial Wellbeing}

An opportunity to socialise with peers was seen as central to adolescent wellbeing by both adolescents and their parents. A 16-year-old Palestinian boy who is blind reported, 'I'd rather get support from someone my age because we need to show adults respect and we cannot say everything we want... Adolescents are more open with each other.' Parents agreed that peer interactions are important. "There are so many challenges. There are some private things that you can't talk about," explained the Syrian mother of several adolescents with disabilities.

While the importance of time with friends is well understood, very few adolescents with disabilities appear to have access to opportunities to socialise outside of school. This leaves those who are out of school 'badly affected' (mother of a 14-year-old Syrian girl who is deaf). In Palestine, where there are more options for schooling, even if education services have quality deficits, the mother of a 17-year-old intellectually impaired girl reported that she had refused the school's request to keep her daughter at home. 'She can just go there to socialise. It is better than staying at home, isn't it?' In Jordan, the mother of an 11-year-old boy who is deaf reported that her son loves football but does not get 'the chance to play, because they want a player to be fast and easy to communicate with'. Similarly, the mother an of 18-year-old Syrian boy with a mobility impairment added that repeated moves - driven by rising rents - had left her son without the opportunity to develop friends: 'Since we came, we moved to around three or four houses, so we barely get to know a neighbourhood before we have to leave it again.'

As is the case with rehabilitation services, our research found that recreational opportunities for adolescents with disabilities appear to be confined to urban areas 
and primarily provided by NGOs. For young people with access, these opportunities are life savers. One Palestine refugee boy living in Jordan reported that he was in a band 'run by the German Jordan University which aims to integrate the blind with the visualised ones'. An 18-year-old Syrian boy with a mobility impairment explained that he had enjoyed playing table tennis with other adolescents with disabilities. However, as with rehabilitation services, as the Syrian refugee crisis becomes more protracted funding shortages are resulting in fewer recreational opportunities for young people: 'There are no more donations so they stopped it.' Adolescents with disabilities in Jordan's informal tented settlements appear to have had no opportunities to socialise with peers as they receive very little NGO support in general, and support for young people with disabilities is non-existent. For example, the mother of several adolescents with disabilities explained that while 'Chinese people' had come one afternoon to play ball, no one else had ever engaged her children.

In Jordan, UNICEF's integrated Makani programme provides over a hundred thousand children and adolescents without disabilities with non-formal education, life skills and opportunities to socialise with one another. However, while Makani programme documents highlight the importance of including adolescents with disabilities, few Makanis - which are run by local NGO and Islamic centres - appear to deliver on this goal. In our sample of adolescents with disabilities living in Jordan, only one - an 18-year-old Syrian girl with a mobility impairment- had ever attended a Makani centre. When asked about her friends, she became very emotional, and her mother explained that she had no friends, as the nearby Makani project had concluded and when it closed her daughter had lost access to the only girl with whom she had an emotional connection. In addition, while most of the adolescents with disabilities and caregivers we spoke with over the course of this research had never heard of Makanis, suggesting that outreach efforts to those with disabilities are negligible, several mothers told us that their adolescents with disabilities had been refused spots at a Makani centre. 'I registered for her and her sisters; they accepted her sisters but didn't accept her," said the mother of a Syrian girl who has a disability. 'I applied many times for the UNICEF; programme they told me that they take those with physical disabilities not hearing disabilities,' added the mother of a 14-year-old Syrian boy who is deaf and mute.

Many out-of-school adolescents with disabilities are homebound and see only their immediate family. 'I wake up at $11 \mathrm{am}$. I sit and use the tablet. I mean, there is nothing. I watch TV, that's it. I don't go out anywhere,' reported a 19-year-old Syrian girl with a mobility impairment. 'I rarely go out of the house to begin with, most of the time I spend on the mobile phone,' added an 18-year-old Syrian boy with a mobility impairment. In some cases adolescents 'choose' to stay inside for practical reasons many of those with vision and hearing impairments are afraid of cars, for example. In most cases, however, adolescents are isolated at home because of stigma. 'The neighbours don't like it when he goes out,' explained the mother of an 11-year-old Syrian boy who is deaf. The society doesn't respect people with disabilities,' added an 18year-old Palestinian girl with an impairment. One 18-year-old Palestinian boy with a mobility impairment told us that he has accepted that this is his life, 'It is just a fleeting life. It will pass by.' Another 14-year-old boy with multiple impairments reported that his favourite possession is a stuffed bear. 'I love it. And it loves me. It is precious to me. When I get sad I talk to it. I feel better when I talk to it. I tell it that I wish I had friends who would talk to me and love me.' 
With few exceptions, adolescents with disabilities and their caregivers were clear that girls with disabilities were doubly disadvantaged when it comes to physical mobility and social opportunities, due to the region's restrictive gender norms. While they recognised that 'staying at home hurts her', they also largely agreed that 'boys can handle it when they go outside' (mother of a 14-year-old Syrian girl who is deaf), even when they are called 'deaf, speechless and unable to walk' (mother of two Syrian boys who are deaf). 'We have to take care of girls. Not only females with disabilities, but all girls. One has to worry about one's daughters,' explained the father of an eighth-grade Palestinian girl who is deaf. Indeed, the mother of two Syrian refugee girls who are blind, when asked why her daughters did not have canes that would allow them to move about more independently, reported: 'They don't need them because they don't go outside.' Parents also noted that girls with disabilities are less likely to have supportive relationships with extended family members, who often see them as limiting the marriage options of their siblings and cousins without disabilities. In Palestine, the mother of a 17-year-old intellectually impaired girl reported that even her daughter's grandmother 'talks about ... and verbally harasses' her daughter.

For some adolescents with disabilities, especially those living in Palestine, the internet is a lifeline to community and information. A 16-year-old Palestinian boy who is blind reported that he is online for more than five hours a day, working with other blind young people from all over the world. They not only play video games, and 'discuss our problems and how we cope in life', but are writing an application that has 'a message to the world that we exist and have a purpose like many others'. An 18year-old Palestinian girl with a mobility impairment reported that she is online hours each day as well: 'I talk to my friends. I post beautiful things on my Facebook account.' In Jordan, however, adolescents' access to ICT appears more limited - primarily due to its cost. When told that a smartphone might open opportunities for her children to communicate with other adolescents with disabilities - and learn via YouTube - the mother of two Syrian adolescents with vision impairments explained that their economic status does not permit access: 'Where do we get these from? They require money. We do not have 10 JDs. If no one helps us we cannot afford them.' Indeed, an 18-year-old Syrian girl who is blind, who up until a month ago had had an 'iPhone that has a version for the special needs' that her family had bought for her and with which she had 'learned all about myself', lamented that it was broken and her family was unable to afford a new one.

Despite the fact that adolescents with disabilities are often more in need of formal psychosocial support than their peers without disabilities, due sometimes to the trauma of losing abilities and other times to the constancy of stigma, we found that adolescents with disabilities' access to formal psychosocial services is even more limited than their access to opportunities to socialise with their peers. An 18-year-old boy in Jordan, paraplegic after being shot in Syria, reported that while he had been offered physiotherapy, he had not been offered support to help him grieve for what he had lost and adjust to his new realities. As a mother of a 17-year-old Palestinian girl with an intellectual impairment explained: 'It is not all about the [physical] treatment.... She also needs psychosocial support.' While a few in-school adolescents with disabilities told us that their schools had counselling departments, adolescents who were attending over-stretched government schools or were already out of school had nowhere to turn but the internet. An 18-year-old Palestinian girl with a mobility impairment noted that 
'no one gives me psychological support.... sometimes I search for videos on YouTube about how to reduce sadness.'

Critical, according to our respondents, is that services and programmes aimed at supporting young people's psychosocial wellbeing focus not only on adolescents with disabilities, but also their families and communities- moving beyond empowerment platitudes, acknowledging reality, and supporting broader change that fosters real agency. An 18-year-old Syrian girl who is blind noted, 'In psychosocial support they tell you how to be strong and how to be a leader... this is fine... [but the problem is] that while people without disabilities can go out and enjoy their life, I can do nothing but stay at home!' She further explained that ultimately she found the training upsetting because 'I started to want things that I couldn't have.' A Syrian mother, who has two children who are deaf, agreed that programming must include the community if change is to become real: "Even if they reach Mars, they will be the same, with the same [negative] perceptions and mentality.' An 18-year-old Palestinian girl, who has a mobility impairment, emphasised the importance of focusing on abilities, rather than disabilities. She was clear that when she reaches Mars, she wants it to be because of her own hard work.

I do not like anyone to give me special treatment or make me feel like I am a subject of pity. I am very competent, and I am not lacking anything... The thing that troubles me the most is that no one listens to me.... I have nothing wrong with me but I feel like they treat me in a special way. The disability is in the mind, not the body.... I don't like people to be worried too much or care too much. I want them to care about me and worry about me, but not in a way that makes me feel helpless. I would like to think on my own.

\subsubsection{Caregiver Psychosocial Wellbeing}

Caregivers' needs for support-psychosocial and financial- and information also emerged in our research as critical not only to their own well-being, but also to that of their children. Without exception, the adolescents with disabilities who were thriving in the face of adversity had parents who had the confidence to proactively seek out and advocate for their adolescents' rights to services and had the emotional capacity to prioritise those needs. In environments where structural neglect is the norm, as is the case in conflict-affected Jordan and Palestine, it is parents who are protecting their children from the oversights of the state. 'It is the parents' treatment that shapes the individual,' explained a 16-year-old Palestinian boy who is blind. A 12-year-old girl in Jordan, who is heavily involved at school and in extra-curricular activities despite the fact that she is blind, agreed that while she loves the opportunities she has, 'the thing that excites me the most, is that my parents are always standing by me.'

Unfortunately, our research highlighted many caregivers of adolescents with disabilities are limited in their ability to fight for their children. They are 
physically exhausted and emotionally overwhelmed by both the broader forces that are shaping the region - including conflict, poverty, high unemployment and limited social cohesion - and the many demands of their children. 'I feel that I'm stressed with all the conditions around. The problem is not because I have two disabled children. I have another two who are non-disabled, who want me to take care of them like their siblings. I'm not an octopus; I can't take care of all of them,' explained the Syrian mother of an 11-year-old boy who is deaf, when asked why she did not learn sign language so that she could better communicate with her son. Some fathers are clearly supportive of their children, as highlighted by the example of a Bedouin father in our research sample who sold his sheep and moved closer to town to make sure his deaf daughter could attend the best possible school. However, more generally the bulk of caregiving responsibility tends to fall on mothers. In many cases, their efforts are poorly rewarded. Some are tormented by neighbours who 'say you deserve all that and call me the mother of the deaf' (Syrian mother of two deaf adolescents) and others are abandoned by their husbands who take new wives in efforts to produce non-disabled children. While a minority of mothers reported that they had at least some friends who had children with disabilities, which makes 'my hardship seem easier', most felt that 'no one can feel my suffering' (Syrian mother of four adolescents who are deaf).

Financial stress only adds to caregivers' woes and leaves them even less able to care for their adolescents with disabilities. However, our research highlighted that even households which were receiving cash transfers reported that it was not enough because neither the PNCTP nor the UNHCR cash assistance programme are indexed to account for the higher costs that often accompany disability. Parents reported that their monthly budgets were often so stretched so thin that they were forced to prioritise needs, choosing between food and hygiene, for example. 'If someone can help us get her diapers, that would be good. Every 10 days she needs a new pack of diapers,' explained the mother of a Syrian adolescent girl with severe physical and intellectual disabilities. This need to choose leaves many parents in a state of near constant anxiety and sadness for what must be given up. A Syrian mother, who has two adolescents who are deaf, explained, 'I get sad, as we were living normally before the crisis.' In Homs, her children had not only had all the medical treatment they needed, with even a bus to take them to and from the clinic, but she had been paid a 'monthly salary of 17,000 Syrian pounds' as the caregiver of children with disabilities. ${ }^{10}$ In Jordan, to make ends meet, she leaves her children during the day in order to clean other people's homes.

Caregivers' needs for information about services for their children are also largely unmet, which in many cases precludes their successful advocacy for their children. The mother of an out-of-school Syrian girl with a mobility impairment reported, for example, that she had never thought to get her daughter - who desperately wants to learn to read - books: 'It never occurred to me to get her books, because there's her mobile phone and the television and us.' The aunt of a 14-year-old Palestinian boy with

\footnotetext{
${ }^{10}$ In December 2018, this was equivalent to $\$ 33 /$ month. However, it was likely worth substantially more when the family first came to Jordan, more than five years ago.
} 
multiple impairments explained that even though she studied social services, she 'needs someone to guide me and tell me where to get disability services'.

\section{Conclusions and Implications for Policy and Practice}

This article has critically interrogated the extent to which traditional framings of neglect centred on parental responsibility are adequately able to capture the realities of adolescents with disabilities. By highlighting adolescents' complex individual needs, which are often exacerbated by stigmatising beliefs about disability, growing up amid protracted conflict and having caregivers who are overburdened, our findings point to the value of embedding a broader structural lens within understandings and measurement of neglect.

It is clear from our research that the multidimensional needs of adolescents with disabilities living in conflict-affected areas remain largely neglected. While there is some attention to education and healthcare, albeit not enough given the number of young people who could be better served if referrals and services were more consistently provided, efforts to support the psychosocial needs of adolescents with disabilities and their caregivers are effectively non-existent, even when they are paid lip service. Indeed, a 16-year-old Palestinian boy who is blind noted that his requests for better services had been met with platitudes rather than action, because his needs were simply not seen as important. "The Minister said "inshallah" [God be willing]. When someone says "inshallah", I figure he might not care about the subject and most likely won't do anything.'

To meet the Sustainable Development Goals' mandate to 'leave no one behind', our research suggests that international actors, including donors and the UN, should consider reframing discourses to better highlight and meet the needs of adolescents with disabilities. This should include broadening the definition of neglect beyond parental and community responsibility to include structural neglect by the state and accepting responsibility for remediating that neglect in contexts where states are unable to independently do so.

Our findings also underscore that there is a pressing need to expand understandings of young people's needs beyond education and healthcare, and to include a focus on their broader capabilities, which especially in adolescence centre on opportunities for social connectedness with peers and for increasing voice and agency in decisionmaking. As an 18-year-old blind girl from Gaza camp in Jordan emphasised: 'Children with disabilities have the right to share in everything in life the same way as those without disabilities - to be treated with justice and equality, and to be protected and supported and given a hand.'

Based on our research, we suggest that concrete efforts to address the neglect of adolescents with disabilities in conflict-affected contexts begin with action in four key areas. First, it is critical to improve accountability among policy-makers and donors, including through the establishment of a national body to ensure effective multisectoral coordination among government agencies and cross-referrals to complementary services, and to promote coordination and information sharing with development partners. In tandem, introducing a disability marker (e.g. the OECD-DAC disability marker), to better track funding and hold government agencies and donors alike to 
account is important, as is enforcing reporting among all UN agencies that is disaggregated by age, gender and disability.

Second, there is an urgent need to agree upon indicators that capture the size and characteristics of the population of adolescents with disabilities and collect the evidence that will enable us to measure progress over time; to undertake service mappings to determine what services are available for immediate referral in any given location, and to invest in research with adolescents themselves to better understand their perspectives and experiences of existing services and programmes, and gaps.

Third, given the multi-dimensional vulnerability of young people with disabilities, it is essential that governments together with donors and development partners move beyond a charity model and prioritise the provision of an integrated package of disability-tailored support that includes accessible, appropriate and quality inclusive education and training, access to primary and disability-specific health and nutritional care, formal psychosocial support services, and social protection programmes that are appropriately targeted and indexed to account for disability. Equally important are safe spaces and recreational opportunities (including through access to digital technologies) that are accessible to adolescents-including girls.

Finally, it is also important to engage and support caregivers of adolescents with disabilities, to ensure that they can support their children; and in tandem to work with service providers and communities to shift the stigma that surrounds disability and to encourage a focus on what young people can, rather than cannot, do.

Open Access This article is distributed under the terms of the Creative Commons Attribution 4.0 International License (http://creativecommons.org/licenses/by/4.0/), which permits unrestricted use, distribution, and reproduction in any medium, provided you give appropriate credit to the original author(s) and the source, provide a link to the Creative Commons license, and indicate if changes were made.

\section{References}

Abu Hamad, B., Jones, N., Samuels, F., Gercama, I., Presler-Marshall, E., Plank, G., Essaid, A., Ebbini, S., Odeh, K., Bazadough, D.,Taleb, H., Amayreh, H. and Sadji, J. (2017) A promise of tomorrow: The effects of UNHCR and UNICEF cash assistance on Syrian refugees in Jordan. London: Overseas Development Institute (www.odi.org/sites/odi.org.uk/files/resource-documents/11877.pdf).

Abu-Hamad, B. Nicola Jones, Elizabeth Presler-Marshall, Paola Pereznieto and Mohammed Shaheen (2019 forthcoming). 'A pathway to social justice? Social protection and disability in the state of Palestine' In R. Jawad, N. Jones and M. Messoub (eds). Social policy in the Middle East and North Africa: The new social protection paradigm and universal coverage. Edward Elgar: Oxford.

Aguilar, C. (2017). Social protection and persons with disabilities. International Social Security Review, 70(4), 45-65.

Bener, A., \& Mohammad, R. R. (2017). Global distribution of consanguinity and their impact on complex diseases: Genetic disorders from an endogamous population. Egyptian Journal of Medical Human Genetics, 18(4), 315-320.

Coope, C., \& Theobald, S. (2006). Children at risk of neglect: Challenges faced by child protection practitioners in Guatemala City. Child Abuse and Neglect, 30, 523-536.

Devereux, S. (2017). Social protection and safety nets in the Middle East and North Africa. Policy in Focus, 14(3), 19-22.

Dubowitz, H. (2014). Child neglect. Pediatric Annals, 43(11), 444- 445.

Dubowitz, H., Pitts, S., \& Black, M. (2004). Measurement of three major subtypes of child neglect. Child Maltreatment, 9(4), 344-356.

GAGE Consortium (2017). Gender and adolescence: Why understanding adolescent capabilities, change strategies and contexts matters. London: Gender and Adolescence: Global Evidence. 
Gerbaka, B. and Almuneef, M. (2014) Child protection in the Arab region: Situation analysis and recommendations. In Conte, J. (ed.) child abuse and neglect worldwide.

Groce, N. and Kett, M. (2014) Youth with disabilities. Working paper 23. London: Leonard Cheshire disability and inclusive development Centre, University College London.

Jones, N., Abu Hamad, B., Odeh, K., Pereznieto, P., Abu Al Ghaib, O., Plank, G., Presler-Marshall, E., \& Shaheen, M. (2016). Every child counts: Understanding the needs and perspectives of children with disabilities in the state of Palestine. London and Jerusalem: ODI and UNICEF.

Jones, N., Presler-Marshall, E., \& Stavropoulou, M. (2018a). Adolescents with disabilities: Enhancing resilience and delivering inclusive development. London: ODI.

Jones, N., Camfield, L., Coast, E., Samuels, F., Abu Hamad, B., Yadete, W., Amayreh, W., Odeh, K. B., Sajdi, J., Rashid, S., Sultan, M., Presler-Marshall, E., \& Malachoswka, A. (2018b). GAGE baseline qualitative research tools. London: GAGE.

Jones, N., Baird, S., \& Lunin, L. (2018c). GAGE research design, sample and methodology. London, UK: Gender and Adolescence: Global Evidence.

Kalmakis, K. and Chandler, G. (2013) Adverse childhood experiences: Towards a clear conceptual meaning. Journal of advanced nursing, 1490-1501.

Laird, S. (2016a). Protecting children from nutritional and medical neglect in sub-Saharan Africa: A fivecountry study. International Journal of Social Welfare, 25, 47-57.

Laird, S. (2016b). 'If parents are punished for asking their children to feed goats': Supervisory neglect in subSaharan Africa. Journal of Social Work, 16(3), 303-321.

Landers, C. (2013) Preventing and responding to violence, abuse, and neglect in early childhood: A technical background document. Child Protection Section UNICEF.

Maxey, M., \& Beckert, T. (2017). Adolescents with disabilities. Adolescent Research Review, 2, 59-75.

Mitra, S., Posarac, A., \& Vick, B. (2013). Disability and poverty in developing countries: A multidimensional study. World Development, 41, 1-18.

Mitra, S., Palmer, M., Kim, H., Mont, D., \& Groce, N. (2017). Extra costs of living with a disability: A review and agenda for research. Disability and Health Journal, 10(4), 475-484.

Roche, S. (2013). Child protection and maltreatment in the Philippines: A systematic review of the literature. Asia and the Pacific Policy Studies, 4(1), 104-128.

Rohwerder, B. (2015) 'Disability inclusion'. Topic Guide. Birmingham: GSDRC, University of Birmingham.

Sen, A. K. (1984). Commodities and capabilities. Oxford: Oxford University Press.

Seth, R. and Raman, S. (2014) What do we know about child neglect? A global perspective. In Conte, J. (ed.) child abuse and neglect worldwide.

Sheehan, P., Sweeny, K., Rasmussen, B., Wils, A., Friedman, H., Mahon, J., Patton, G., Sawyer, S., Howard, E., Symons, J., Stenberg, K., Chalasani, S., Maharaj, N., Reavley, N., Shi, H., Fridman, M., Welsh, A., Nsofor, E., \& Laski, L. (2017). Building the foundations for sustainable development: A case for global investment in the capabilities of adolescents. The Lancet, 390(10104), 1792-1806.

Sirdah, M. M. (2014). Consanguinity profile in the Gaza strip of Palestine: Large-scale community-based study. European Journal of Medical Genetics, 57(2), 90-94.

Stalker, K., \& McArthur, K. (2012). Child abuse, child protection and disabled children: A review of recent research. Child Abuse Review, 21, 24-40.

Straus, M. A., \& Kantor, G. K. (2005). Definition and measurement of neglectful behavior: Some principles and guidelines. Child Abuse \& Neglect, 29(1), 19-29.

Tang, C. (2008) Working toward a conceptual definition of child neglect. Journal of health and human services administration. 356-384.

UNDESA (n.d.) Refugees and migrants with disabilities. https://www.un. org/development/desa/disabilities/refugees_migrants_with_disabilities.html

UNESCO (2018) 'Education and disability: Analysis of data from 49 countries'. Information paper 49. Paris: UNESCO.

UNFPA (UN Population Fund) (2014) 'The power of 1.8 billion: Adolescents, youth, and the transformation of the future', in state of world population 2014. New York: UNFPA.

van Diesen, A. (2017) Social protection for children and their families in the Middle East and North Africa: Where child rights meet smart economics.

WHO. (2006). Preventing child maltreatment: A guide to taking action and generating evidence. Geneva: WHO.

WHO and World Bank. (2011). World report on disability. Geneva: WHO.

World Bank. (2017). Forcibly displaced: Toward a development approach supporting refugees, the internally displaced and their hosts. Washington, DC: World Bank. 